\title{
Stereotactic body radiation therapy (SBRT) for prostate cancer in men with large prostates $\left(\geq 50 \mathrm{~cm}^{3}\right)$
}

Einsley Janowski ${ }^{1 \dagger}$, Leonard N Chen ${ }^{1 \dagger}$, Joy S Kim', Siyuan Lei ${ }^{1}$, Simeng Suy ${ }^{1}$, Brian Collins ${ }^{1}$, John Lynch², Anatoly Dritschilo ${ }^{1}$ and Sean Collins ${ }^{1 *}$

\begin{abstract}
Background: Patients with large prostate volumes have been shown to have higher rates of genitourinary and gastrointestinal toxicities after conventional radiation therapy for prostate cancer. The efficacy and toxicity of stereotactic body radiation therapy (SBRT), which delivers fewer high-dose fractions of radiation treatment, is unknown for large prostate volume prostate cancer patients. We report our early experience using SBRT for localized prostate cancer in patients with large prostate volumes.

Methods: 57 patients with prostate volumes $\geq 50 \mathrm{~cm}^{3}$ prior to treatment with SBRT for localized prostate carcinoma and with a minimum follow up of two years were included in this retrospective review of prospectively collected data. Treatment was delivered using Cyberknife (Accuray) with doses of 35-36.25 Gy in 5 fractions. Biochemical control was assessed using the Phoenix definition. Toxicities were scored using the CTCAE v.4. Quality of life was assessed using the American Urological Association (AUA) Symptom Score and the Expanded Prostate Cancer Index Composite (EPIC)-26.

Results: 57 patients (23 low-, 25 intermediate- and 9 high-risk according to the D'Amico classification) at a median age of 69 years (range, 54-83 years) received SBRT with a median follow-up of 2.9 years. The median prostate size was $62.9 \mathrm{~cm}^{3}$ (range $50-138.7 \mathrm{~cm}^{3}$ ). 33.3\% of patients received ADT. The median pre-treatment prostate-specific antigen (PSA) was $6.5 \mathrm{ng} / \mathrm{ml}$ and decreased to a median PSA of $0.4 \mathrm{ng} / \mathrm{ml}$ by 2 years $(p<0.0001)$. A mean baseline AUA symptom score of 7.5 significantly increased to 13 at 1 month $(p=0.001)$ and returned to baseline by 3 months $(p=0.21)$. 23\% of patients experienced a late transient urinary symptom flare in the first two years following treatment. Mean baseline EPIC bowel scores of 95.8 decreased to 78.1 at 1 month $(p<0.0001)$, but subsequently improved to 93.5 three months $(p=0.08)$. The 2 -year actuarial incidence rates of $\mathrm{GU}$ and $\mathrm{Gl}$ toxicity $\geq$ grade 2 were $49.1 \%$ and $1.8 \%$, respectively. Two patients (3.5\%) experienced grade 3 urinary toxicity, and no patient experienced grade 3 gastrointestinal toxicity.
\end{abstract}

Conclusions: SBRT for clinically localized prostate cancer was well tolerated in men with large prostate volumes.

Keywords: Prostate cancer, Large prostate, SBRT, CyberKnife, Common toxicity criteria (CTC), Quality of life, EPIC, AUA, SF-12, Urinary symptom flare

\footnotetext{
*Correspondence: SPC9@georgetown.edu

'Equal contributors

'Department of Radiation Medicine, Georgetown University Hospital,

Washington DC 20007, USA

Full list of author information is available at the end of the article
} 


\section{Introduction}

External beam radiation therapy (EBRT) and brachytherapy are the primary radiation modalities for clinically localized prostate cancer. Over the last few decades, external beam radiation delivery has evolved from 2-D delivery to 3-D conformal and, subsequently, to IMRT and stereotactic body radiation therapy (SBRT). These advances in radiation treatment planning and radiation delivery have allowed for higher doses of radiation to be delivered, thereby improving biochemical progression free survival [1-4] and reducing the rates of salvage therapy in high risk patients [5]. For men with localized prostate cancer, the typical treatment with dose-escalated EBRT involves fractionated radiation therapy, using daily doses of 1.8-2.0 Gy for eight to nine weeks. SBRT delivers fewer, high-dose fractions of radiation, providing a number of advantages, including a more convenient, shortened time course as well as a theoretical improvement in cancer response to larger daily radiation fractions [6]. Early data from trials of SBRT show SBRT to be comparably effective in prostate cancer treatment [7-15].

Brachytherapy, which involves placing radioactive sources into prostate tissue, is another radiation treatment option for patients who prefer an abbreviated course of treatment, either as a single modality in low risk patients or in combination with external beam therapy in intermediate and high risk patients [16,17]. However, brachytherapy is not appropriate for all patients, including patients with unfavorable anatomy [18], including pubic arch interference, those who cannot tolerate anesthesia, patients with significant medical co-morbidities, or those who are at increased risk for treatment-related complications. For instance, patients with a history of prior TURP treatment or with baseline urinary obstructive symptoms and/or large prostate sizes ( $>50 \mathrm{cc}$ ) are considered to be at an increased risk for urinary incontinence or urinary obstruction respectively. Indeed, the relationship between acute toxicity and large prostate size has been reported for brachytherapy [19-23], although one study has shown that biochemical control and acceptable late toxicities may be achieved in patients presenting with large volume prostates [24]. Some patients with large prostates may become candidates for brachytherapy with neoadjuvant androgen deprivation therapy (ADT) to shrink the prostate; however, this is achieved at the expense of toxicities of hormone therapy, including hot flashes, loss of libido, obesity, osteoporosis, and risk for diabetes and cardiovascular disease [25].

Acute toxicity associated with external beam radiation commonly involves the genitourinary and gastrointestinal systems, including irritative or obstructive urinary dysfunction and bowel frequency and urgency [26]. Advances in external beam radiation technique [27-29] and utilization of daily prostate localization with IGRT [30] have been shown to reduce the rates of toxicity. Like in brachytherapy, another factor that impacts the development of external beam radiation-induced toxicity is the volume of the prostate. The link between prostate volume and increasing acute radiation toxicity has been well described following 3-D conformal radiation [26,31] and IMRT [32].

While early data from SBRT shows a comparable toxicity profile to that of IMRT, the efficacy and toxicity of SBRT for prostate cancer patients with large prostate volumes remain unclear. The purpose of this study was to evaluate the influence of prostate volume on acute and late urinary and bowel toxicity in patients treated with SBRT.

\section{Methods}

This study is a retrospective review of prospectively collected data on 57 consecutively treated patients with prostate volumes $\geq 50 \mathrm{~cm}^{3}$, who received hypofractionated stereotactic body radiotherapy at Medstar-Georgetown University Hospital as monotherapy for histologicallyconfirmed localized prostate cancer. Risk category was defined using the D'Amico classification [16]. Clinical stage was assigned according to the 6th edition of the American Joint Committee on Cancer definitions. Exclusion criteria included less than two years of clinical follow-up, clinical involvement of lymph nodes, distant metastases on pretreatment imaging, prior prostate cancer-directed therapy, or prior pelvic irradiation. Institutional review board approval was obtained for this analysis.

\section{Treatment planning and delivery}

Prior to treatment planning, 4 gold fiducials were placed into the prostate. Approximately seven days after fiducial placement, patients underwent MR imaging followed shortly thereafter by a thin-cut CT scan. Fused CT and MR images were then used for treatment planning. The fiducial placement and CT/MRI simulation procedures have been previously described [33]. The gross tumor volume (GTV) was defined as the prostatic capsule and the proximal seminal vesicles up to the point that the left and right seminal vesicles separated. The GTV was then further expanded by $3 \mathrm{~mm}$ posteriorly and $5 \mathrm{~mm}$ in all other directions to create a CTV. No further expansion was made from CTV to PTV. Treatment planning was performed using Multiplan (Accuray Inc., Sunnyvale, CA). Figure 1a shows an axial view of a typical treatment plan. 35-36.25 Gy was given to the PTV in 5 fractions over 2 weeks to a mean prescription isodose line of $77 \%$. The rectum, bladder, testes, penile bulb and membranous urethra and prostatic urethra were contoured and evaluated with a dose-volume histogram. A typical dose volume histogram is shown in Figure 1b. Dose constraints have been previously reported [7]. Target position was verified every $30-60$ seconds during 


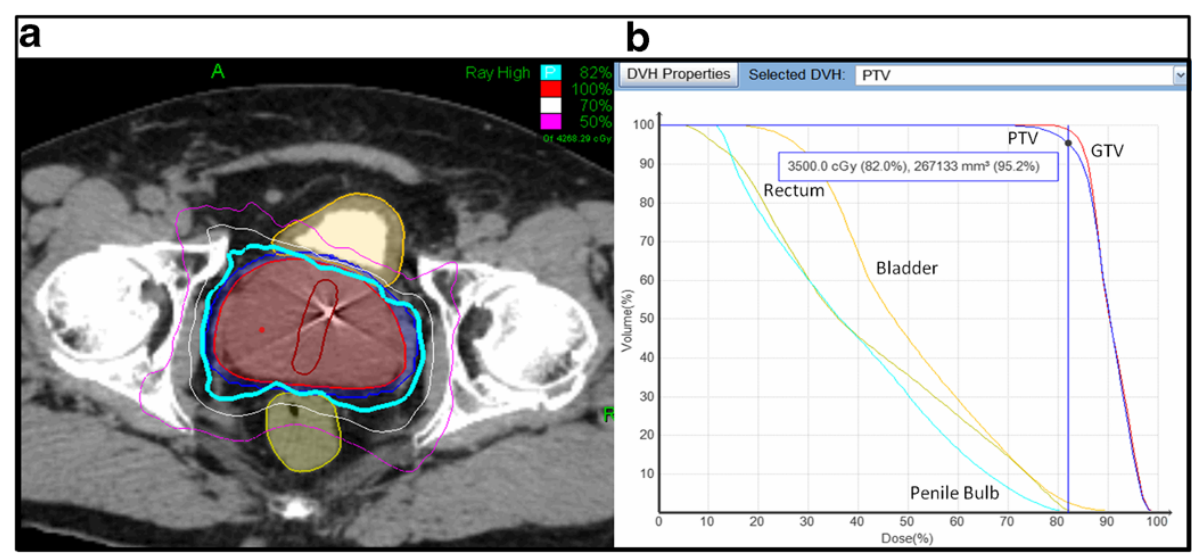

Figure 1 Treatment Planning and Delivery. (a) The volumes represent the GTV (red), PTV (blue), rectum (light green), and bladder (yellow). The prescription isodose line (82\%) is denoted by the thick cyan line. (b) A typical dose-volume histogram (DVH) for Cyberknife treatment of a prostate cancer patient is shown, revealing doses to the GTV, PTV, and nearby critical structures, including the rectum, bladder, and penile bulb.

treatment using orthogonal $\mathrm{kV}$ images as previously described [33,34].

\section{Pretreatment assessment and follow-up}

Prostate volume assessment was either performed by the patient's treating urologist at the time of biopsy and/or at our institution during fiducial placement. In addition, patient assessments included clinical examination, a digital rectal exam, PSA level, and a quality of life (QOL) questionnaire. These assessments were performed prior to the initiation of stereotactic body radiotherapy, at 1 and 3 months post-treatment, and every 3 months thereafter. Biochemical failure was defined as a PSA rise of $\geq 2 \mathrm{ng} / \mathrm{mL}$ above the nadir [35]. Acute and late toxicities were scored using the Common Terminology Criteria for Adverse Events (CTCAE) Version 4.0. Toxicity is defined as acute, occurring within 6 months of completing treatment, and late reflecting those events occurring later than 6 months. At each follow-up visit, toxicity events were scored independently for each of the different toxicity types, and the highest GU and GI toxicities were determined for each patient. The QOL questionnaires evaluated urinary, bowel, and erectile functions using the American Urological Association Symptom Score (AUA) [36], the Expanded Prostate Cancer Index Composite (EPIC) short form [37], and the 12-item Medical Outcomes Study Short Form (SF-12) version 2 questionnaires [38]. Late urinary symptom flare was defined as having both an AUA score $\geq 15$ with an increase of $\geq 5$ points above baseline six months after the completion of SBRT.

\section{Statistical analysis}

Student's t-test and chi-square analysis were used to assess differences in ongoing PSA and quality of life scores in comparison to baseline. As previously reported, late urinary symptom flare was defined as an increase of $\geq 5$ points above baseline with a degree of severity in the moderate to severe range (AUA score $\geq 15$ ) [39]. The flare was considered resolved when either the AUA score dropped to $<15$ or the score returned to $<5$ points above the patient's pre-treatment baseline. QOL data from time points in which more than $80 \%$ of patients completed the questionnaires were included in the analysis. A QOL change of one-half standard deviation (SD) from the baseline QOL score, defined as the minimal important difference (MID), was used to denote a clinically significant change in the QOL score [40]. The two-sided paired Wilcoxon rank-sum test was used to calculate the significance of differences in the mean scores on follow-up as compared to the baseline values. Parameters were identified as significant if the two-tailed p-value was less than 0.05. MedCalc ${ }^{\bullet}$ version 11.6.1.0 was used for the statistical analyses.

\section{Results}

Fifty-seven men, who met the inclusion criteria, were treated at our institution between August 2008 and May 2011, with a median clinical follow-up of 2.9 years (range, 1.9-3.6 years). The median prostate size was $62.9 \mathrm{~cm}^{3}$ (range $50-138.7 \mathrm{~cm}^{3}$ ). Their baseline characteristics are summarized in Table 1 . Of note, our patients were $54 \%$ Caucasian with a median age of 69 years old (range, 54-83 years). By D'Amico classification, 23 were low-, 25 intermediate-, and 9 high risk. 33.3\% of our patients received androgen deprivation therapy as prescribed by their urologist for either combined modality prostate cancer treatment or management of urinary symptoms. $78.9 \%$ of patients were treated with 36.25 Gy and $19.3 \%$ of patients were treated with $35 \mathrm{~Gy}$.

The median pre-treatment PSA was $6.5 \mathrm{ng} / \mathrm{mL}(0.2-24 \mathrm{ng} /$ $\mathrm{mL}$ ), and, at 2 years, the median PSA decreased to $0.4 \mathrm{ng} / \mathrm{mL}$ 
Table 1 Patient characteristics

\begin{tabular}{|c|c|c|}
\hline Age (yrs) & & Percent patients $(n=57)$ \\
\hline & $<60$ & 7 \\
\hline & $60-69$ & 45.6 \\
\hline & 70-79 & 35.1 \\
\hline & $\geq 80$ & 12.3 \\
\hline \multicolumn{3}{|l|}{ Race } \\
\hline & White & 54.4 \\
\hline & Black & 40.4 \\
\hline & Other & 5.3 \\
\hline \multicolumn{3}{|c|}{ Pre-treatment PSA (ng/ml) } \\
\hline & $\leq 10$ & 77.2 \\
\hline & $10<\mathrm{PSA} \leq 20$ & 15.8 \\
\hline & $>20$ & 7 \\
\hline \multicolumn{3}{|l|}{ T-Stage } \\
\hline & $\mathrm{T} 1 \mathrm{c}$ & 73.7 \\
\hline & $\mathrm{T} 2 \mathrm{a}$ & 12.3 \\
\hline & $\mathrm{T} 2 \mathrm{~b}$ & 12.3 \\
\hline & $\mathrm{T} 2 \mathrm{c}$ & 1.8 \\
\hline \multicolumn{3}{|c|}{ Gleason score } \\
\hline & 5 & 1.8 \\
\hline & 6 & 44 \\
\hline & 7 & 42 \\
\hline & 8 & 10.4 \\
\hline & Other & 1.8 \\
\hline \multicolumn{3}{|l|}{ Risk group } \\
\hline & Low risk & 40.4 \\
\hline & Intermediate risk & 43.9 \\
\hline & High risk & 15.7 \\
\hline \multicolumn{3}{|c|}{ Hormone treatment } \\
\hline & Yes & 33 \\
\hline & No & 67 \\
\hline \multicolumn{3}{|l|}{ Dose } \\
\hline & $35 \mathrm{~Gy}$ & 19.3 \\
\hline & $35.25 \mathrm{~Gy}$ & 1.8 \\
\hline & $36.25 \mathrm{~Gy}$ & 78.9 \\
\hline \multicolumn{3}{|c|}{$a_{1 A}$ Inhibitor (Flomax) } \\
\hline & Yes & 37 \\
\hline & No & 63 \\
\hline
\end{tabular}

$(0.1-1.7 \mathrm{ng} / \mathrm{mL})(p<0.0001)$ (Figure 2). There was one biochemical failure, occurring in an intermediate risk patient, who was found to have widely metastatic disease to the bone 12 months post-treatment. The overall two-year actuarial biochemical relapse free survival was $98 \%$.

Baseline quality of life demographics for our patients are shown in Table 2. Pre-treatment EPIC results reveal that our patient population had baseline mild-moderate urinary incontinence (score 86.4) and irritative/obstructive (score 86 ) symptoms. The low sexual function scores may be partially related to the $33.3 \%$ use of androgen deprivation therapy. Pre-treatment AUA scores correlate with the findings on EPIC, revealing that the majority of our treatment population had either mild (49.1\%) or moderate $(43.9 \%)$ baseline urinary bother, with the mean AUA score being $9.1 \pm 6.6$ (range, 0-33). Baseline SF-12 scores for our patient group were comparable to those of a similarly aged general population.

The prevalence of GU and GI toxicities following treatment is shown in Table 3. The prevalence of single symptoms as well as the highest GI and GU toxicity per patient are depicted independently for each follow-up visit. Actuarial incidence rates of late grade 2 and $3 \mathrm{GU}$ toxicities are shown in Figure 3a. $49.1 \%$ of patients experienced grade 2 urinary toxicities, requiring initiation or increase in alpha antagonist medications. Urinary grade 3 toxicities were low, being observed in $3.5 \%$ of patients, with one patient developing grade 3 retention at 12 months requiring a TURP and another patient developing grade 3 hematuria at 6 months requiring cauterization.

Analyses of urinary function health related quality of life are shown in Figures 3b-f. Evaluation of AUA score (Figure $3 \mathrm{~b}$ ) reveals two distinct peaks at 1 month and 9 months post-treatment. A mean baseline AUA symptom score of 7.5 significantly increased to 13 at 1 month $(p=0.001)$ and returned to baseline at 3 months $(p=0.21)$. Another small peak was seen between 6 to 9 months, where the mean AUA went from 9 to 9.7. Indeed, 23\% of patients experienced a late transient urinary symptom flare ( $\geq 6$ months after completing treatment) in the first two years following treatment (Figure 3c), with the median time to flare being 9 months and the median duration of flare being 3 months. As shown in Figure 3d, at baseline, 37\% of patients reported using alpha antagonists pre-treatment. New or increased alpha antagonist use, graded as a grade 2 toxicity (Table 3), correlated with the increased AUA score and peaked at 1 month, with $67 \%$ of patients requiring change or initiation of alpha antagonist medications. Another small increase in alpha antagonist use was seen from 6 to 9 months post-treatment, also correlating with the second increased AUA score. At 24 months alpha antagonist use was higher than baseline but significantly decreased from the peak of 1 month, with $48 \%$ of patients reporting use at two years. Analysis of the changes in EPIC scores (Figures 3e-f) also showed two significant dips at 1 month and at 9 months. As shown in Figure 3e, mean baseline EPIC urinary obstructive scores of 86 significantly decreased to 75.5 at one month $(p<0.0002)$, but subsequently improved to 84 at 3 months $(p=0.39)$. Another transient decrease in EPIC scores occurred at 9 months, with 


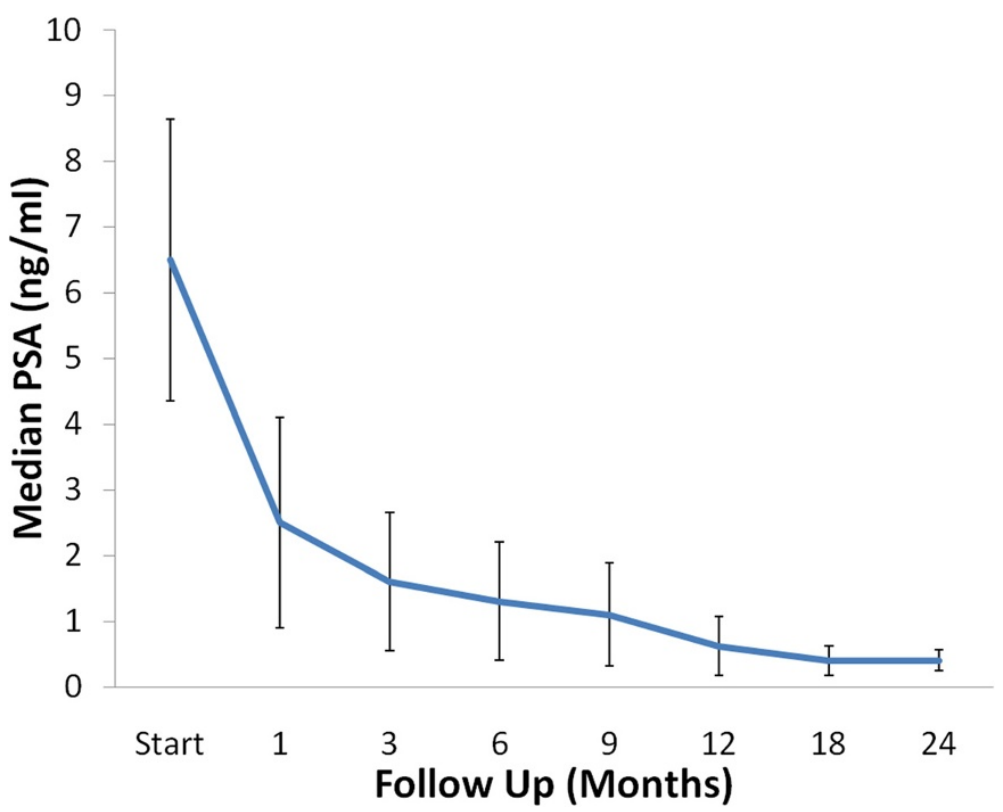

Figure 2 Median PSA changes. The median pre-treatment prostate-specific antigen (PSA) was $6.5 \mathrm{ng} / \mathrm{ml}$, and, at 2 years, the median PSA decreased to $0.4 \mathrm{ng} / \mathrm{ml}(p<0.0001)$.

the 6 month score of 85 decreasing to 90 at 9 months $(p<0.008)$. EPIC urinary obstructive scores subsequently improved back to baseline at 12 months $(p=0.13)$ and remained stable, with the 2 year score being 87.4. The mean baseline EPIC urinary incontinence score of 86.1 (Figure 3f) was not significantly changed throughout the 2 year posttreatment follow up.

Actuarial incidence rates of late grade 2 and 3 GI toxicities are shown in Figure 4a. A grade 2 GI toxicity of increased frequency of bowel movements was seen in one patient (1.8\%); there were no grade 3 gastrointestinal toxicities. The bowel quality of life scores are shown in Figure 4b. The mean EPIC bowel score of 95.8 significantly decreased to 78.1 at 1 month $(p<0.0001)$, but

Table 2 Baseline QOL characteristics

\begin{tabular}{ll}
\hline EPIC Individual Domain Score (mean) & \\
\hline Urinary Incontinence & 86.4 \\
Urinary Irritative/Obstructive & 86 \\
Bowel & 95.8 \\
Sexual & 41.3 \\
Hormonal & 88.2 \\
Baseline SF-12 Score & \\
PCS ( $n=56)$ & $48.9(22.1-63.1)$ \\
MCS ( $n=56)$ & $56.7(31.1-65.9)$ \\
Baseline AUA Score & Patient No. (\% patients) \\
0-7 (mild) & $28(49.1 \%)$ \\
8-19 (moderate) & $25(43.9 \%)$ \\
$\geq 20$ & $3(5.3 \%)$ \\
\hline
\end{tabular}

subsequently improved to 93.5 at three months $(p=0.08)$. Another much smaller decline was seen at 9 months $(p<0.005)$, but improved at 12 months and remained steady, with a score of 94.7 at two years $(p=0.32)$.

\section{Discussion}

A variety of treatment modalities for prostate cancer are available to patients, with retrospective series showing comparable biochemical local control rates for low-risk patients treated with surgery, brachytherapy, and external beam radiation [41]. However, not all treatment modalities are appropriate for all patients, and treatment recommendation decisions are often stratified by patient convenience and preference, toxicity-related quality of life, and cancer risk category. Although IMRT is the standard external beam modality to treat clinically localized prostate cancer, disadvantages include a treatment course of 8-9 weeks. SBRT delivers highly conformal, high dose radiation in 5 or fewer treatment fractions, providing convenience to the patients and a theoretical improvement in cancer response to larger daily radiation fractions [6].

A growing body of evidence has established the efficacy of SBRT for prostate cancer treatment, with multiple single institution studies of SBRT reporting a biochemical relapse free survival of $90-100 \%$ with a median follow up of 5 years or more [8,10,12,42-45]. In this SBRT study, our two year biochemical relapse free survival of a diverse group of low-, intermediate-, and high risk patients is consistent with that of other institutions. 
Table 3 Prevalence of CTC graded GI and GU toxicities

\begin{tabular}{|c|c|c|c|c|c|c|c|c|c|}
\hline Toxicity & Grade & Start & 1 & 3 & 6 & 9 & 12 & 18 & 24 \\
\hline \multirow[t]{3}{*}{ Diarrhea } & 0 & $100 \%$ & $53 \%$ & $84 \%$ & $75 \%$ & $83 \%$ & $88 \%$ & $94 \%$ & $94 \%$ \\
\hline & 1 & $0 \%$ & $35 \%$ & $16 \%$ & $23 \%$ & $15 \%$ & $12 \%$ & $6 \%$ & $6 \%$ \\
\hline & 2 & $0 \%$ & $12 \%$ & $0 \%$ & $2 \%$ & $2 \%$ & $0 \%$ & $0 \%$ & $0 \%$ \\
\hline \multirow[t]{3}{*}{ Proctitis } & 0 & $86 \%$ & $79 \%$ & $93 \%$ & $92 \%$ & $100 \%$ & $98 \%$ & $100 \%$ & $100 \%$ \\
\hline & 1 & $14 \%$ & $21 \%$ & $7 \%$ & $8 \%$ & $0 \%$ & $2 \%$ & $0 \%$ & $0 \%$ \\
\hline & 2 & $0 \%$ & $0 \%$ & $0 \%$ & $0 \%$ & $0 \%$ & $0 \%$ & $0 \%$ & $0 \%$ \\
\hline \multirow[t]{3}{*}{ Rectal Bleeding } & 0 & $100 \%$ & $91 \%$ & $95 \%$ & $100 \%$ & $98 \%$ & $98 \%$ & $96 \%$ & $96 \%$ \\
\hline & 1 & $0 \%$ & $9 \%$ & $5 \%$ & $0 \%$ & $2 \%$ & $2 \%$ & $4 \%$ & $4 \%$ \\
\hline & 2 & $0 \%$ & $0 \%$ & $0 \%$ & $0 \%$ & $0 \%$ & $0 \%$ & $0 \%$ & $0 \%$ \\
\hline \multirow[t]{3}{*}{ Highest GI } & 0 & $67 \%$ & $46 \%$ & $77 \%$ & $75 \%$ & $82 \%$ & $86 \%$ & $91 \%$ & $91 \%$ \\
\hline & 1 & $33 \%$ & $42 \%$ & $23 \%$ & $23 \%$ & $16 \%$ & $14 \%$ & $9 \%$ & $9 \%$ \\
\hline & 2 & $0 \%$ & $12 \%$ & $0 \%$ & $2 \%$ & $2 \%$ & $0 \%$ & $0 \%$ & $0 \%$ \\
\hline \multirow[t]{4}{*}{ Hematuria } & 0 & $98 \%$ & $95 \%$ & $93 \%$ & $94 \%$ & $91 \%$ & $90 \%$ & $91 \%$ & $94 \%$ \\
\hline & 1 & $2 \%$ & $5 \%$ & $4 \%$ & $2 \%$ & $4 \%$ & $4 \%$ & $7 \%$ & $2 \%$ \\
\hline & 2 & $0 \%$ & $0 \%$ & $4 \%$ & $2 \%$ & $4 \%$ & $4 \%$ & $0 \%$ & $2 \%$ \\
\hline & 3 & $0 \%$ & $0 \%$ & $0 \%$ & $2 \%$ & $2 \%$ & $2 \%$ & $2 \%$ & $2 \%$ \\
\hline \multirow[t]{3}{*}{ Dysuria } & 0 & $89 \%$ & $65 \%$ & $77 \%$ & $90 \%$ & $80 \%$ & $92 \%$ & $91 \%$ & $92 \%$ \\
\hline & 1 & $11 \%$ & $35 \%$ & $23 \%$ & $10 \%$ & $20 \%$ & $8 \%$ & $9 \%$ & $8 \%$ \\
\hline & 2 & $0 \%$ & $0 \%$ & $0 \%$ & $0 \%$ & $0 \%$ & $0 \%$ & $0 \%$ & $0 \%$ \\
\hline \multirow[t]{3}{*}{ Incontinence } & 0 & $75 \%$ & $67 \%$ & $71 \%$ & $79 \%$ & $74 \%$ & $77 \%$ & $76 \%$ & $73 \%$ \\
\hline & 1 & $21 \%$ & $30 \%$ & $27 \%$ & $17 \%$ & $24 \%$ & $21 \%$ & $19 \%$ & $27 \%$ \\
\hline & 2 & $4 \%$ & $4 \%$ & $2 \%$ & $4 \%$ & $2 \%$ & $2 \%$ & $6 \%$ & $0 \%$ \\
\hline \multirow[t]{3}{*}{ Urinary frequency/ urgency } & 0 & $39 \%$ & $16 \%$ & $55 \%$ & $62 \%$ & $48 \%$ & $52 \%$ & $48 \%$ & $58 \%$ \\
\hline & 1 & $61 \%$ & $82 \%$ & $45 \%$ & $35 \%$ & $50 \%$ & $44 \%$ & $48 \%$ & $42 \%$ \\
\hline & 2 & $0 \%$ & $2 \%$ & $0 \%$ & $4 \%$ & $2 \%$ & $4 \%$ & $4 \%$ & $0 \%$ \\
\hline \multirow[t]{4}{*}{ Retention } & 0 & $67 \%$ & $33 \%$ & $57 \%$ & $54 \%$ & $57 \%$ & $56 \%$ & $54 \%$ & $44 \%$ \\
\hline & 1 & $33 \%$ & $26 \%$ & $20 \%$ & $21 \%$ & $19 \%$ & $15 \%$ & $19 \%$ & $29 \%$ \\
\hline & 2 & $0 \%$ & $53 \%$ & $29 \%$ & $30 \%$ & $29 \%$ & $31 \%$ & $31 \%$ & $36 \%$ \\
\hline & 3 & $0 \%$ & $0 \%$ & $0 \%$ & $0 \%$ & $0 \%$ & $2 \%$ & $2 \%$ & $2 \%$ \\
\hline \multirow[t]{4}{*}{ Highest GU } & 0 & $33 \%$ & $5 \%$ & $25 \%$ & $32 \%$ & $26 \%$ & $32 \%$ & $32 \%$ & $37 \%$ \\
\hline & 1 & $63 \%$ & $53 \%$ & $51 \%$ & $46 \%$ & $49 \%$ & $42 \%$ & $39 \%$ & $35 \%$ \\
\hline & 2 & $10 \%$ & $89 \%$ & $50 \%$ & $40 \%$ & $46 \%$ & $42 \%$ & $44 \%$ & $39 \%$ \\
\hline & 3 & $0 \%$ & $0 \%$ & $0 \%$ & $2 \%$ & $2 \%$ & $2 \%$ & $4 \%$ & $4 \%$ \\
\hline
\end{tabular}

Treatment of prostate cancer patients with large prostates can provide new challenges. Indeed, radiation treatment of such patients is associated with increased acute urinary toxicity compared to patients presenting with small prostates. NCCN guidelines currently recommend caution for brachytherapy treatment of patients with large prostates based on widely published data relating the increased frequency of acute urinary obstructive and irritative symptoms requiring catherization or other interventions $[19,21,22,26,46,47]$.

The relationship between prostate volume and external beam radiation related toxicity has not been as widely documented, but the correlation between increasing urinary toxicity and increasing prostate volume also appears to hold true for 3D conformal radiation and IMRT [31,32]. Pinkawa et al. prospectively assessed health related quality of life in patients with prostate volumes stratified by prostate size less than or greater than or equal to $44 \mathrm{~cm}^{3}$, finding that patients with large prostates had significantly worse urinary bother scores immediately after radiation, but that the two groups were not different at 2 and 16 months after treatment [31]. Aizer et al. retrospectively reviewed the genitourinary toxicity of patients treated with IMRT stratified by prostate size into less than 


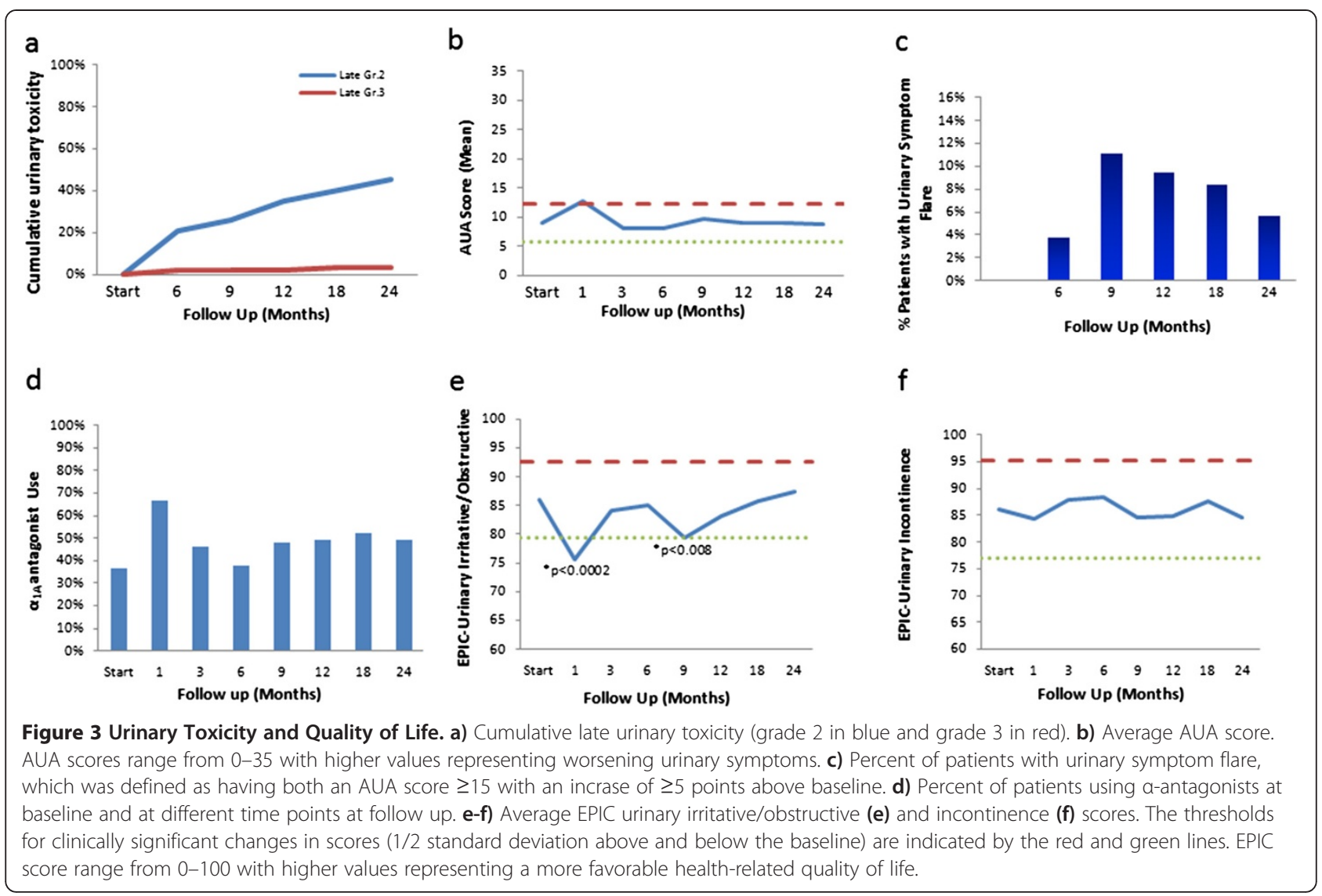

or greater than $50 \mathrm{~cm}^{3}$, demonstrating the patients with large prostate volumes had significantly higher acute urinary frequency/urgency and grade $3 \mathrm{GU}$ toxicity [32]. There was no difference between the two groups in urinary retention or incontinence.

In addition to the convenience of the timing of treatment, intra-fraction image guidance during treatment allows for smaller CTV-PTV margins, thereby minimizing dose to nearby critical structures to reduce treatment related toxicity. SBRT treatment of localized prostate cancer in patients with large prostates was well tolerated by patients at our institution. Our largely grade 1-2 toxicities were symptomatically managed. If initiation or increase of alpha antagonists was not sufficient to manage
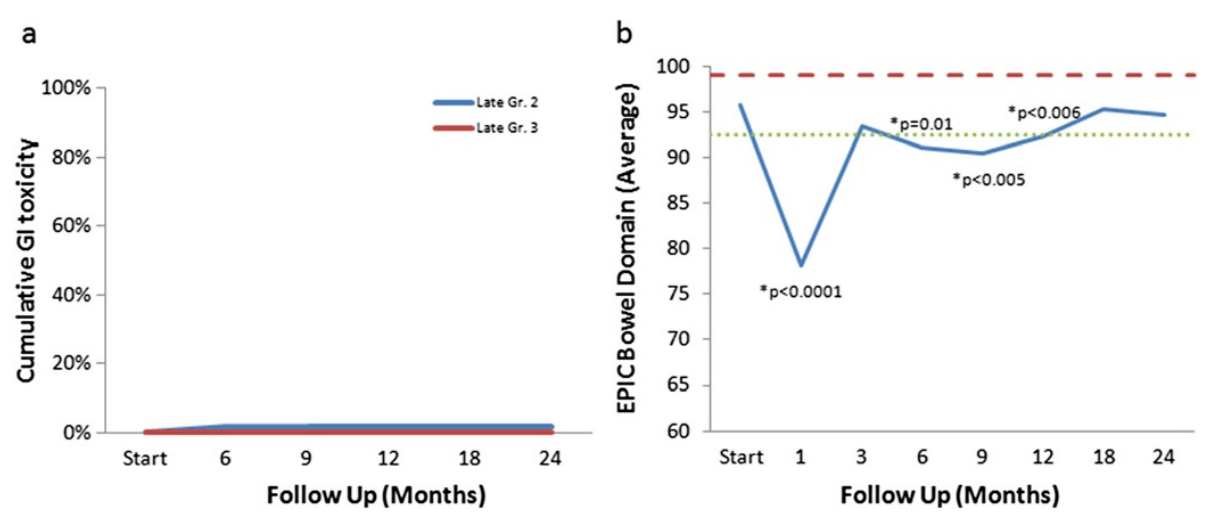

Figure 4 Gastrointestinal Toxicity and Quality of Life. a) Cumulative late gastrointestinal toxicity (grade 2 in blue and grade 3 in red). b) Average EPIC bowel domain scores. The thresholds for clinically significant changes in scores (1/2 standard deviation above and below the baseline) are indicated by the red and green lines. EPIC score range from 0-100 with higher values representing a more favorable health-related quality of life. 
symptoms, a short 1 week course of steroids were given with symptomatic improvement, as previously reported [48]. Grade 3 urinary toxicities were infrequent in our SBRT patients, occurring less commonly than predicted by the prior large prostate radiation studies using different radiation modalities $[31,32,49]$. When compared to our previous publication of prostate cancer patients treated with SBRT not stratified by prostate volume, it appears that patients with large prostate volumes do have a higher rate of grade 2 or higher toxicity [7]. Our results are consistent with those of Pinkawa and Aizer regarding the trend towards increased acute irritative obstructive symptoms and toxicity in patients with large prostates treated with external beam radiation.

Late urinary symptom flares have been commonly observed in prostate cancer patients treated with radiation. This was first observed by Cesaretti et al. in 2003 as occurring a median of 23.9 months after brachytherapy [50]. Keyes et al. showed that a greater baseline International Prostate Symptom Score was positively correlated with the development of the late urinary symptom flare [49]. This late urinary symptom flare has also been described in SBRT [7,9]. While the etiology of the flare is unknown, theories include late radiation damage to the smooth muscle or vasculature of the prostate, causing late radiation induced prostatitis/urethritis. In our patients, these late urinary symptom flares were observed, and the majority resolved with conservative management.

Grade 2 or higher GI toxicities were rare in our patients. Assessment of quality of life showed an acute worsening of EPIC bowel scores at one month posttreatment. These findings are comparable to those of conventionally fractionated radiation therapy $[26,51,52]$, and the symptoms were managed conservatively with either observation or medications. To our knowledge, this is the first study to report a late GI symptom flare with SBRT. Interestingly, a link between late urinary symptom flare and rectal toxicity in brachytherapy patients has been previously described and may relate to a patient's ability to repair radiation-induced DNA damage [49].

\section{Conclusions}

We report here, the first study on toxicity and health related quality of life in patients presenting with large prostate volumes treated with SBRT. This report supports the conclusion that patients with larger prostate volumes can be safely treated with SBRT, and gastrointestinal and urinary toxicity rates are comparable, if not improved, to those observed in conventionally fractionated radiation therapy and brachytherapy. Based on continued reports on the safety and efficacy of SBRT as well as patient preference for a shorter treatment course, SBRT utilization is likely to continue to increase. Our institutional experience adds to the growing body of evidence supporting the effectiveness and safety of SBRT even for larger prostate volumes.

\section{Consent}

Written informed consent was obtained from patients for the publication of this report and any accompanying images.

\section{Abbreviations \\ ADT: Androgen deprivation therapy; AUA: American Urological Association; CT: Computed tomography; CTCAE: Common Terminology Criteria for Adverse Events; CTV: Clinical target volume; DVH: Dose-volume histogram; EBRT: External beam radiation therapy; EPIC: Expanded prostate index composite; GI: Gastro-Intestinal; GTV: Gross target volume; GU: Genito-Urinary; IGRT: Image-Guided Radiation Therapy; IMRT: Intensity Modulated Radiation Therapy; MRI: Magnetic Resonance Imaging; PTV: Planning target volume; QoL: Quality of life; SBRT: Stereotactic body radiation therapy.}

\section{Competing interests}

SP Collins and BT Collins serve as clinical consultants to Accuray Inc. The authors declare that they have no competing interests.

\section{Authors' contributions}

EJ and LC are lead authors, who participated in data collection, data analysis, manuscript drafting, table/figure creation and manuscript revision. $A B$ aided in the quality of life data collection and maintained the patient database. JK aided in the quality of life data collection and maintained the patient database, aided in data collection, and participated in initial data interpretation. SL is the dosimetrist who developed the majority of patients treatment plans, and contributed to the dosimetric data analysis and interpretation. BC participated in the design and coordination of the study. SS aided in statistical analysis, quality of life analysis and manuscript revision. $A D$ is a senior author who aided in drafting the manuscript. $J$ is a senior author who aided in drafting the manuscript. SC was the principal investigator who initially developed the concept of the study and the design, aided in data collection, drafted and revised the manuscript. All authors read and approved the final manuscript.

\section{Acknowledgments}

This work was supported by the James and Theodore Pedas Family Foundation and NIH grant P30CA051008.

\section{Author details}

'Department of Radiation Medicine, Georgetown University Hospital, Washington DC 20007, USA. ²Department of Urology, Georgetown University Hospital, Washington DC 20007, USA.

Received: 25 July 2014 Accepted: 18 October 2014 V.

\section{References}

1. Dearnaley DP, Sydes MR, Graham JD, Aird EG, Bottomley D, Cowan RA Huddart RA, Jose CC, Matthews JH, Millar J, Moore AR, Morgan RC, Russell JM, Scrase CD, Stephens RJ, Syndikus I, Parmar MK: Escalated-dose versus standard-dose conformal radiotherapy in prostate cancer: first results from the MRC RT01 randomised controlled trial. Lancet Oncol 2007, 8(6):475-487.

2. Viani GA, Stefano EJ, Afonso SL: Higher-than-conventional radiation doses in localized prostate cancer treatment: a meta-analysis of randomized, controlled trials. Int J Radiat Oncol Biol Phys 2009, 74(5):1405-1418.

3. Zietman AL, Bae K, Slater JD, Shipley WU, Efstathiou JA, Coen JJ, Bush DA, Lunt M, Spiegel DY, Skowronski R, Jabola BR, Rossi CJ: Randomized trial comparing conventional-dose with high-dose conformal radiation therapy in early-stage adenocarcinoma of the prostate: long-term results from proton radiation oncology group/american college of radiology 95-09. J Clin Oncol 2010, 28(7):1106-1111. 
4. Kuban DA, Tucker SL, Dong L, Starkschall G, Huang EH, Cheung MR, Lee AK, Pollack A: Long-term results of the M. D. Anderson randomized dose-escalation trial for prostate cancer. Int J Radiat Oncol Biol Phys 2008, 70(1):67-74.

5. Jacobs BL, Zhang Y, Skolarus TA, Wei JT, Montie JE, Miller DC, Hollenbeck BK: Comparative effectiveness of external-beam radiation approaches for prostate cancer. Eur Urol 2014, 65(1):162-168.

6. Fowler JF: The radiobiology of prostate cancer including new aspects of fractionated radiotherapy. Acta Oncol 2005, 44(3):265-276.

7. Chen LN, Suy S, Uhm S, Oermann EK, Ju AW, Chen V, Hanscom HN, Laing S, Kim JS, Lei S, Batipps GP, Kowalczyk K, Bandi G, Pahira J, McGeagh KG, Collins BT, Krishnan P, Dawson NA, Taylor KL, Dritschilo A, Lynch JH, Collins SP: Stereotactic body radiation therapy (SBRT) for clinically localized prostate cancer: the Georgetown University experience. Radiat Oncol 2013, 8:58

8. Freeman DE, King CR: Stereotactic body radiotherapy for low-risk prostate cancer: five-year outcomes. Radiat Oncol 2011, 6:3.

9. Ju AW, Wang H, Oermann EK, Sherer BA, Uhm S, Chen VJ, Pendharkar AV, Hanscom HN, Kim JS, Lei S, Suy S, Lynch JH, Dritschilo A, Collins SP: Hypofractionated stereotactic body radiation therapy as monotherapy for intermediate-risk prostate cancer. Radiat Oncol 2013, 8:30.

10. Katz AJ, Santoro M, Diblasio F, Ashley R: Stereotactic body radiotherapy for localized prostate cancer: disease control and quality of life at 6 years. Radiat Oncol 2013, 8(1):118

11. King CR, Freeman D, Kaplan I, Fuller D, Bolzicco G, Collins SP, Meier R, Wang J, Kupelian P, Steinberg M, Katz A: Stereotactic body radiotherapy for localized prostate cancer: pooled analysis of multi-insitutional prospective trials. Radiat Ther Oncol 2013. In Press.

12. King CR, Brooks JD, Gill H, Presti JC Jr: Long-term outcomes from a prospective trial of stereotactic body radiotherapy for low-risk prostate cancer. Int J Radiat Oncol Biol Phys 2011, 82(2):877-882.

13. King $C R$, Collins SP, Fuller D, Wang PC, Kupelian P, Steinberg M, Katz A: Health related quality of life after stereotactic body radiotherapy for localized prostate cancer: results from a multi-institutional consortium of prospective trials. Int J Radiat Oncol Biol Phys 2013. in press.

14. McBride SM, Wong DS, Dombrowski JJ, Harkins B, Tapella P, Hanscom HN, Collins SP, Kaplan ID: Hypofractionated stereotactic body radiotherapy in low-risk prostate adenocarcinoma: Preliminary results of a multi-institutional phase 1 feasibility trial. Cancer 2012, 118(15):3681-3690.

15. Miles EF, Lee WR: Hypofractionation for prostate cancer: a critical review. Semin Radiat Oncol 2008, 18(1):41-47.

16. D'Amico AV, Whittington R, Malkowicz SB, Schultz D, Blank K, Broderick GA, Tomaszewski JE, Renshaw AA, Kaplan I, Beard CJ, Wein A: Biochemical outcome after radical prostatectomy, external beam radiation therapy, or interstitial radiation therapy for clinically localized prostate cancer. JAMA 1998, 280(11):969-974.

17. Masson S, Persad R, Bahl A: HDR brachytherapy in the management of high-risk prostate cancer. Adv Urol 2012, 2012:980841.

18. Wallner K, Ellis W, Russell K, Cavanagh W, Blasko J: Use of TRUS to predict pubic arch interference of prostate brachytherapy. Int J Radiat Oncol Bio Phys 1999, 43(3):583-585.

19. Gelblum DY, Potters L, Ashley R, Waldbaum R, Wang XH, Leibel S: Urinary morbidity following ultrasound-guided transperineal prostate seed implantation. Int J Radiat Oncol Biol Phys 1999, 45(1):59-67.

20. Krupski T, Bissonette EA, Petroni GR, Theodorescu D: The impact of prostate volume following neoadjuvant androgen deprivation on quality of life and voiding symptoms in patients undergoing permanent prostate brachytherapy. Eur Urol 2003, 43(5):467-472.

21. Locke J, Ellis W, Wallner K, Cavanagh W, Blasko J: Risk factors for acute urinary retention requiring temporary intermittent catheterization after prostate brachytherapy: a prospective study. Int J Radiat Oncol Biol Phys 2002, 52(3):712-719.

22. Niehaus A, Merrick GS, Butler WM, Wallner KE, Allen ZA, Galbreath RW, Adamovich $\mathrm{E}$ : The influence of isotope and prostate volume on urinary morbidity after prostate brachytherapy. Int J Radiat Oncol Biol Phys 2006, 64(1):136-143

23. Sherertz $T$, Wallner $K$, Wang $H$, Sutlief $S$, Russell $K$ : Long-term urinary function after transperineal brachytherapy for patients with large prostate glands. Int J Radiat Oncol Biol Phys 2001, 51(5):1241-1245.

24. Le H, Rojas A, Alonzi R, Hughes R, Ostler P, Lowe G, Bryant L, Hoskin P: The influence of prostate volume on outcome after high-dose-rate brachytherapy alone for localized prostate cancer. Int J Radiat Oncol Biol Phys 2013, 87(2):270-274

25. Gaztanaga M, Crook J: Androgen deprivation therapy: minimizing exposure and mitigating side effects. J Natl Compr Canc Netw 2012, 10(9):1088-1095. quiz 1088, 1096.

26. Sanda MG, Dunn RL, Michalski J, Sandler HM, Northouse L, Hembroff L, Lin X, Greenfield TK, Litwin MS, Saigal CS, Mahadevan A, Klein E, Kibel A, Pisters LL, Kuban D, Kaplan I, Wood D, Ciezki J, Shah N, Wei JT: Quality of life and satisfaction with outcome among prostate-cancer survivors. N Engl J Med 2008, 358(12):1250-1261.

27. Michalski JM, Yan Y, Watkins-Bruner D, Bosch WR, Winter K, Galvin JM, Bahary JP, Morton GC, Parliament MB, Sandler HM: Preliminary toxicity analysis of 3-dimensional conformal radiation therapy versus intensity modulated radiation therapy on the high-dose arm of the Radiation Therapy Oncology Group 0126 prostate cancer trial. Int J Radiat Oncol Biol Phys 2013, 87(5):932-938.

28. Zelefsky MJ, Fuks Z, Happersett L, Lee HJ, Ling CC, Burman CM, Hunt M, Wolfe T, Venkatraman ES, Jackson A, Skwarchuk M, Leibel SA: Clinical experience with intensity modulated radiation therapy (IMRT) in prostate cancer. Radiother Oncol 2000, 55(3):241-249.

29. Zelefsky MJ, Levin EJ, Hunt M, Yamada Y, Shippy AM, Jackson A, Amols HI: Incidence of late rectal and urinary toxicities after three-dimensional conformal radiotherapy and intensity-modulated radiotherapy for localized prostate cancer. Int J Radiat Oncol Biol Phys 2008, 70(4):1124-1129.

30. Zelefsky MJ, Kollmeier M, Cox B, Fidaleo A, Sperling D, Pei X, Carver B, Coleman J, Lovelock M, Hunt M: Improved clinical outcomes with high-dose image guided radiotherapy compared with non-IGRT for the treatment of clinically localized prostate cancer. Int J Radiat Oncol Biol Phys 2012, 84(1):125-129.

31. Pinkawa M, Fischedick K, Asadpour B, Gagel B, Piroth MD, Nussen S, Eble MJ: Toxicity profile with a large prostate volume after external beam radiotherapy for localized prostate cancer. Int J Radiat Oncol Biol Phys 2008, 70(1):83-89.

32. Aizer AA, Anderson NS, Oh SC, Yu JB, McKeon AM, Decker RH, Peschel RE: The impact of pretreatment prostate volume on severe acute genitourinary toxicity in prostate cancer patients treated with intensity-modulated radiation therapy. Int J Radiat Oncol Biol Phys 2011, 79(2):379-384.

33. Lei S, Piel N, Oermann EK, Chen V, Ju AW, Dahal KN, Hanscom HN, Kim JS, Yu X, Zhang G, Collins BT, Jha R, Dritschilo A, Suy S, Collins SP: Six-dimensional correction of intra-fractional prostate motion with CyberKnife stereotactic body radiation therapy. Front Oncol 2011, 1:48.

34. Xie Y, Djajaputra D, King CR, Hossain S, Ma L, Xing L: Intrafractional motion of the prostate during hypofractionated radiotherapy. Int J Radiat Oncol Biol Phys 2008, 72(1):236-246.

35. Roach M 3rd, Hanks G, Thames H Jr, Schellhammer P, Shipley WU, Sokol GH, Sandler H: Defining biochemical failure following radiotherapy with or without hormonal therapy in men with clinically localized prostate cancer: recommendations of the RTOG-ASTRO Phoenix Consensus Conference. Int J Radiat Oncol Biol Phys 2006, 65(4):965-974.

36. Barry MJ, Fowler FJ Jr, O'Leary MP, Bruskewitz RC, Holtgrewe HL, Mebust WK, Cockett AT: The American Urological Association symptom index for benign prostatic hyperplasia. The Measurement Committee of the American Urological Association. J Urol 1992, 148(5):1549-1557. discussion 1564

37. Wei JT, Dunn RL, Litwin MS, Sandler HM, Sanda MG: Development and validation of the expanded prostate cancer index composite (EPIC) for comprehensive assessment of health-related quality of life in men with prostate cancer. Urology 2000, 56(6):899-905.

38. Ware J Jr, Kosinski M, Keller SD: A 12-item short-form health survey: construction of scales and preliminary tests of reliability and validity. Med Care 1996, 34(3):220-233.

39. Crook J, Fleshner N, Roberts C, Pond G: Long-term urinary sequelae following 125iodine prostate brachytherapy. J Urol 2008, 179(1):141-145. discussion 146

40. Norman GR, Sloan JA, Wyrwich KW: Interpretation of changes in healthrelated quality of life: the remarkable universality of half a standard deviation. Med Care 2003, 41(5):582-592.

41. Kupelian PA, Potters L, Khuntia D, Ciezki JP, Reddy CA, Reuther AM, Carlson TP, Klein EA: Radical prostatectomy, external beam radiotherapy $<72 \mathrm{~Gy}$, external beam radiotherapy $>$ or $=72 \mathrm{~Gy}$, 
permanent seed implantation, or combined seeds/external beam radiotherapy for stage T1-T2 prostate cancer. Int I Radiat Oncol Biol Phys 2004, 58(1):25-33.

42. Kang JK, Cho CK, Choi CW, Yoo S, Kim MS, Yang K, Yoo H, Kim JH, Seo YS, Lee $\mathrm{DH}$, Jo M: Image-guided stereotactic body radiation therapy for localized prostate cancer. Tumori 2011, 97(1):43-48.

43. Katz AJ, Santoro M, Ashley R, Diblasio F, Witten M: Stereotactic body radiotherapy for organ-confined prostate cancer. BMC Urol 2010, 10:1.

44. King CR, Brooks JD, Gill H, Pawlicki T, Cotrutz C, Presti JC Jr: Stereotactic body radiotherapy for localized prostate cancer: interim results of a prospective phase II clinical trial. Int I Radiat Oncol Biol Phys 2009, 73(4):1043-1048

45. Madsen BL, Hsi RA, Pham HT, Fowler JF, Esagui L, Corman J: Stereotactic hypofractionated accurate radiotherapy of the prostate (SHARP), 33.5 Gy in five fractions for localized disease: first clinical trial results. Int I Radiat Oncol Biol Phys 2007, 67(4):1099-1105.

46. Krupski TL, Saigal CS, Litwin MS: Variation in continence and potency by definition. J Urol 2003, 170(4 Pt 1):1291-1294.

47. Lee N, Wuu CS, Brody R, Laguna JL, Katz AE, Bagiella E, Ennis RD: Factors predicting for postimplantation urinary retention after permanent prostate brachytherapy. Int J Radiat Oncol Biol Phys 2000, 48(5):1457-1460

48. Woo JA, Chen LN, Bhagat A, Oermann EK, Kim JS, Moures R, Yung T, Lei S, Collins BT, Kumar D, Suy S, Dritschilo A, Lynch JH, Collins SP: Clinical characteristics and management of late urinary symptom flare following stereotactic body radiation therapy for prostate cancer. Front Oncol 2014, 4:122.

49. Keyes M, Miller S, Moravan V, Pickles T, Liu M, Spadinger I, Lapointe V, Morris WJ: Urinary symptom flare in 712125 I prostate brachytherapy patients: long-term follow-up. Int J Radiat Oncol Biol Phys 2009, 75(3):649-655.

50. Cesaretti JA, Stone NN, Stock RG: Urinary symptom flare following I-125 prostate brachytherapy. Int J Radiat Oncol Biol Phys 2003, 56(4):1085-1092.

51. Gray PJ, Paly JJ, Yeap BY, Sanda MG, Sandler HM, Michalski JM, Talcott JA, Coen JJ, Hamstra DA, Shipley WU, Hahn SM, Zietman AL, Bekelman JE, Efstathiou JA: Patient-reported outcomes after 3-dimensional conformal, intensity-modulated, or proton beam radiotherapy for localized prostate cancer. Cancer 2013, 119(9):1729-1735.

52. Hamstra DA, Conlon AS, Daignault S, Dunn RL, Sandler HM, Hembroff AL, Zietman AL, Kaplan I, Ciezki J, Kuban DA, Wei JT, Sanda MG, Michalski JM: Multi-institutional prospective evaluation of bowel quality of life after prostate external beam radiation therapy identifies patient and treatment factors associated with patient-reported outcomes: the PROSTQA experience. Int J Radiat Oncol Biol Phys 2013, 86(3):546-553.

doi:10.1186/s13014-014-0241-3

Cite this article as: Janowski et al: Stereotactic body radiation therapy (SBRT) for prostate cancer in men with large prostates $\left(\geq 50 \mathrm{~cm}^{3}\right)$.

Radiation Oncology 2014 9:241.

\section{Submit your next manuscript to BioMed Central and take full advantage of:}

- Convenient online submission

- Thorough peer review

- No space constraints or color figure charges

- Immediate publication on acceptance

- Inclusion in PubMed, CAS, Scopus and Google Scholar

- Research which is freely available for redistribution

Submit your manuscript at www.biomedcentral.com/submit
Ciomed Central 